\title{
Dilatation in the femoral vascular bed does not cause retrograde relaxation of the iliac artery in the anaesthetized pig
}

\author{
F. Markos,' ${ }^{\prime}$ T. Ruane-O'Hora, ${ }^{\prime}$ H. M. Snow, ${ }^{\prime}$ R. Kelly, ${ }^{2}$ C. Wainwright, ${ }^{3}$ K. Skene, ${ }^{3}$ A. J. Drake- \\ Holland $^{3}$ and M. I. M. Noble ${ }^{4}$ \\ Department of Physiology, University College Cork, Cork, Ireland \\ Hatter Institute for Cardiovascular Research, University of Cape Town, Cape Town, South Africa \\ 3 School of Pharmacy and Life Sciences, Robert Gordon University, Aberdeen, UK \\ 4 Cardiovascular Medicine, University of Aberdeen Medical School, Aberdeen, UK
}

Received 24 April 2008, revision requested 7 June 2008, revision received 9 June 2008, accepted 13 June 2008 Correspondence: F. Markos, Department of Physiology, University College Cork, Cork, Ireland.

E-mail:f.markos@ucc.ie

\begin{abstract}
Aim: We tested the hypothesis that dilatation of a feeding artery may be elicited by transmission of a signal through the tissue of the arterial wall from a vasodilated peripheral vascular bed.

Methods: In eight pentobarbital anaesthetized pigs, acetylcholine (ACh, an endothelium-dependent vasodilator) was injected intra-arterially above (upstream) and below (downstream) a test segment of the left iliac artery, the diameter of which was measured continuously by sonomicrometry.

Results: Under control conditions, ACh injections upstream and downstream of the test segment caused dilatation. Downstream injection dilated the peripheral arterioles, resulting in increased blood flow and proximal dilatation. This is a shear stress, nitric oxide (NO)-dependent response. The experiment was then repeated after applying a stenosis to prevent the increased flow caused by downstream injection of $\mathrm{ACh}$; the stenosis was placed either above the site of diameter measurement to allow retrograde conduction, or below that site to prevent distally injected ACh reaching the measurement site. Under these conditions, downstream injection of ACh had a minimal effect on the shear stress of the test segment with no increase in test segment diameter. This was not due to endothelial damage or dysfunction as injection of ACh upstream still caused a large increase in test segment diameter.

Conclusions: Our results indicate that dilatation of the feeding artery of a vasodilated bed is caused by increased shear stress within the feeding artery and not via a signal transmitted through the arterial wall from below.

Keywords endothelium, endothelium-dependent hyperpolarizing factor, nitric oxide, shear stress.
\end{abstract}

An important physiological response to vasodilatation of peripheral resistance vessels is dilatation of the feeding artery, as studied by Hilton (1959). Hilton was not to know about the developments in knowledge of arterial physiology since 1959 and the critical importance of the influence of the endothelium, specifically endothelium-derived diffusible factors that are delivered to arterial smooth muscle cells. Furthermore, peripheral dilatation of resistance vessels, with the consequent increase in blood flow, generates increased shear stress between blood and the arterial wall of the feeding artery causing dilatation of that artery through 
a now very thoroughly studied mechanism (Snow et al. 2001, Markos et al. 2002, Kelly et al. 2006, Kelly \& Snow 2007). In addition to the shear stress-mediated increase in arterial diameter, Hilton (1959) postulated that dilatation in a peripheral arterial bed also caused retrograde spread of dilatation to the proximal segment of the artery. This hypothesis was based on the observation that when the cat femoral artery was cut through and re-connected, the dilatatory response to increased arterial flow induced by skeletal muscle contraction was abolished in the artery proximal to the section. Hilton was able to exclude a neural reflex mechanism, and in view of the slow conduction speed of the signal $\left(10 \mathrm{~cm} \mathrm{~s}^{-1}\right)$ postulated that the signal was conducted through the smooth muscle layer of the artery.

In a recent study (Kelly \& Snow 2007) the iliac artery and vein were connected via a shunt which enabled precise, controlled changes in flow and shear stress through graded opening and closing of the shunt. The shear stress-dependent dilatation of the artery was preserved even though it was disconnected from the distal artery, a direct contradiction to Hilton's result. Therefore, we attempted to study this phenomenon further. Specifically, we tested whether a section of the iliac artery of the pig, a conduit artery, dilates following a downstream vasodilation which does not elicit an increase in flow at the measurement site. Acetylcholine (ACh) injection was used to induce vasodilation downstream of two measurement sites on the left iliac artery, the two sites (about $2-3 \mathrm{~cm}$ apart) were separated by an adjustable snare which prevented the increase in blood flow from affecting the proximal measurement area. $\mathrm{ACh}$ injection induces responses mediated by both endothelium-derived hyperpolarizing factor (EDHF) (Griffith et al. 2002) and nitric oxide (NO) (Griffith 2002).

\section{Materials and methods}

This investigation was carried out under licenses issued by the Department of Health Ireland as directed by the Cruelty to Animals Act Ireland and EU Statutory Instructions.

\section{Surgery and instrumentation}

Eight female landrace pigs $(20-25 \mathrm{~kg})$ were sedated with ketamine (18 $\left.\mathrm{mg} \mathrm{kg}^{-1}\right)$ and xylazine $\left(2.7 \mathrm{mg} \mathrm{kg}^{-1}\right)$ and then anaesthetized with a bolus, followed by a continuous infusion of sodium pentobarbital (induction $30 \mathrm{mg} \mathrm{kg}^{-1}$ i.v.; maintenance $6 \mathrm{mg} \mathrm{kg}^{-1} \mathrm{~h}^{-1}$ i.v.). Endtidal carbon dioxide partial pressure $\left(\mathrm{P}_{\mathrm{ET}} \mathrm{CO}_{2}\right)$ was measured continuously with a capnograph (Surgivet, Waukesha, WI, USA). Figure 1 shows an example of the experimental preparation.

Following tracheotomy animals were ventilated with $40 \% \mathrm{O}_{2}$ in room air using a Palmer pump. The eight pigs were prepared as described by Kelly et al. (2006) with two exceptions, (1) instead of occlusive snares, we used adjustable snares made of non-traumatic material, so that flow-limiting stenoses could be applied, and (2) artery diameter was measured at just one site. The left iliac artery was dissected from the aortic bifurcation to the deep femoral branch, a length of $8-10 \mathrm{~cm}$; the sacral artery was ligated. Ultrasonic crystals were placed on diametrically opposite sides of the artery for continuous measurement of the diameter, using a sonomicrometer. An ultrasonic transit time flow meter (Transonic Systems, Ithaca, NY, USA) was placed upstream of the snare and crystals. A cannula was inserted into the inferior mesenteric artery for injection of ACh upstream (proximal) to the left iliac artery measurement site. Another cannula was inserted into the left deep femoral artery for downstream (distal) injection of ACh. A third

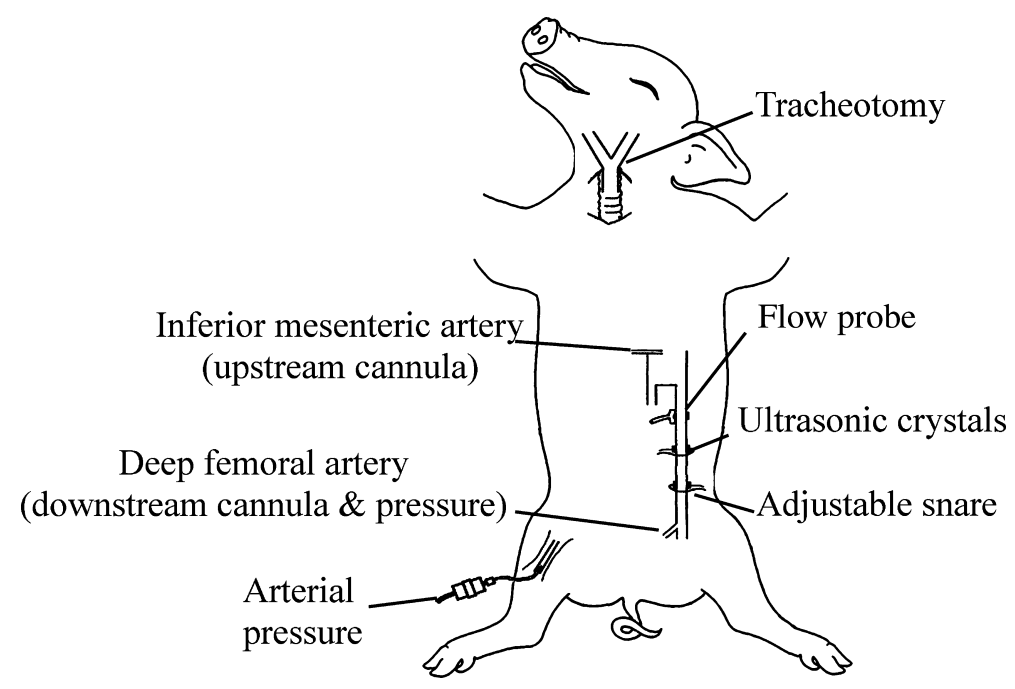

Figure I Schematic diagram of the experimental preparation. In some experiments, the adjustable snare was placed between the flow probe and the ultrasonic crystals, e.g. the experiment illustrated in Figure 2. 
cannula for arterial pressure measurement was inserted into the right femoral artery; pressure was measured with a standard strain gauge manometer (Grass, Quincy, IL, USA). In addition a second pressure manometer (Grass) was connected to this cannula via a three-way tap in four experiments to assess pressure below the stenosis. At the end of the experiments, animals were killed using a lethal intravenous injection of pentobarbitone.

\section{Measurements}

The crystals measure the outer diameter of the artery, this was then corrected for the crystal lens effect and arterial wall thickness in the calculation of the internal diameter (Snow et al. 2001, Markos et al. 2002). The haemodynamic signals were recorded using Power lab preamplifiers and software (AD Instruments, Chalgrove, UK), and a Compaq PC. Shear stress was calculated continuously on-line by CHART 5 software (AD Instruments). The protocol consisted of control measurements of the dilatatory responses of the iliac artery to upstream and downstream injections of ACh (Fig. 2, doses in Table 1). This sequence was then repeated after applying a stenosis with sufficient constriction to prevent an increase in flow during peripheral vasodilatation (Fig. 2). At first, we placed the stenosis proximal to the crystals to ensure that it did not impair retrograde electrotonic transmission; later we obtained identical results with the stenosis distal to the crystals,

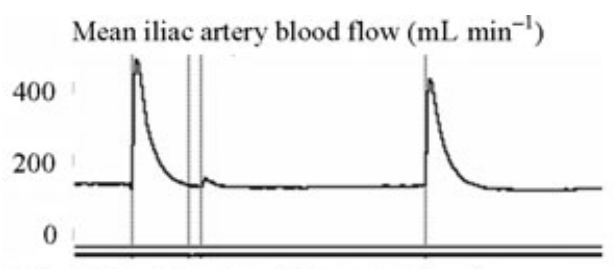

4.6 Mean diameter of iliac artery $(\mathrm{mm})$

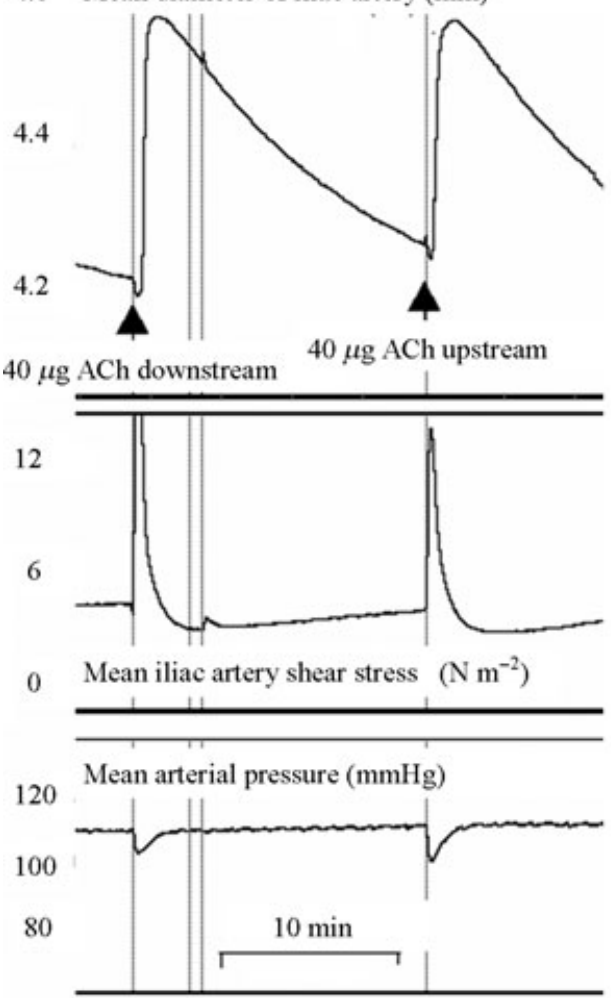

Control

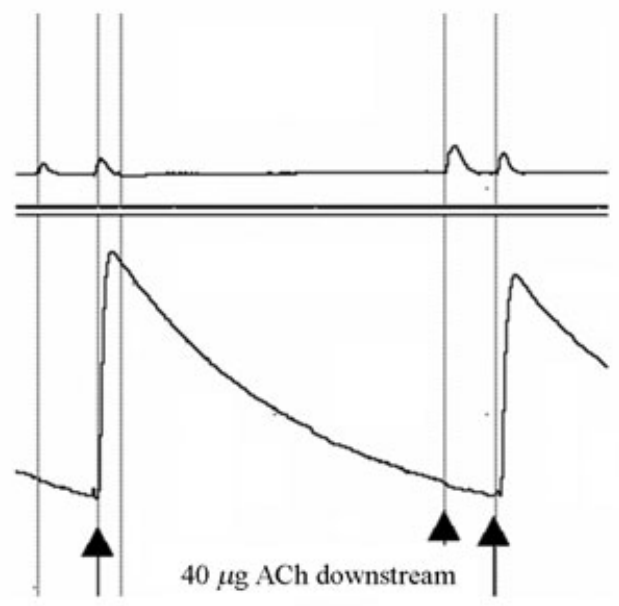

$40 \mu \mathrm{g} \mathrm{ACh}$ downstream $\quad 40 \mu \mathrm{g}$ ACh upstream

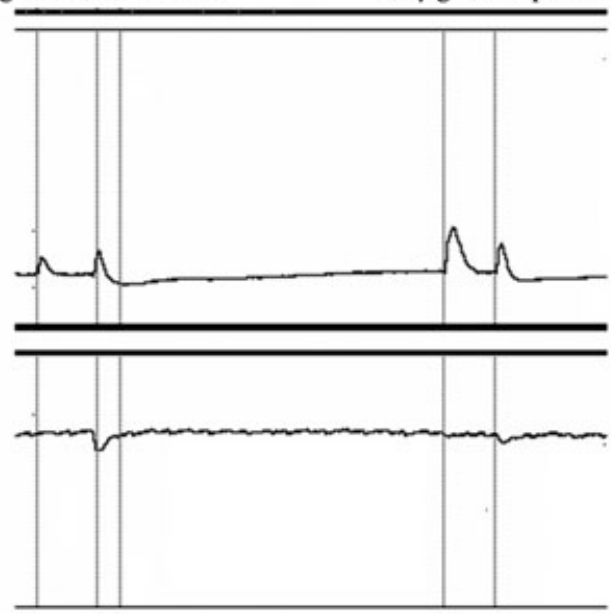

Iliac artery stenosis

Figure 2 Signals recorded in the anaesthetized pig. Top: Mean iliac blood flow, mean iliac artery diameter, mean shear stress of the iliac artery and mean arterial pressure. Left panel: Control conditions, acetylcholine (ACh) injected downstream at first arrow and upstream at second arrow; both injections caused dilatation. Right panel: In the presence of iliac artery stenosis proximal to the diameter measurement, ACh injected upstream at first and third arrows, downstream at second arrow. Only the upstream injection caused dilatation. Downstream injection was associated with only minor increases in flow or shear stress, and was without effect on arterial diameter. 
Table I Individual responses in eight experiments. The first two injections of ACh in each experiment were made under control conditions; the third and fourth injections of $\mathrm{ACh}$ in each experiment were made in the presence of a stenosis to restrict the flow and shear stress increases

\begin{tabular}{|c|c|c|c|c|}
\hline $\begin{array}{l}\text { Experiment number and } \\
\text { intervention }\end{array}$ & $\begin{array}{l}\text { Change in blood flow } \\
\left(\mathrm{mL} \min ^{-1}\right)\end{array}$ & $\begin{array}{l}\text { Change in shear stress } \\
\left(\mathrm{N} \mathrm{m}^{-2}\right)\end{array}$ & $\begin{array}{l}\text { Change in arterial } \\
\text { pressure } \\
(\mathrm{mmHg})\end{array}$ & $\begin{array}{l}\text { Change in arterial } \\
\text { diameter } \\
(\mathrm{mm})\end{array}$ \\
\hline \multicolumn{5}{|l|}{ I } \\
\hline Upstream ACh $40 \mu \mathrm{g}$ & +329 & +20.0 & -10.5 & +0.223 \\
\hline Downstream ACh $40 \mu \mathrm{g}$ & +345 & +13.7 & -7.8 & +0.129 \\
\hline \multicolumn{5}{|l|}{ Stenosis } \\
\hline Upstream ACh $40 \mu \mathrm{g}$ & +1 & +0.01 & -2.1 & +0.100 \\
\hline Downstream ACh $40 \mu \mathrm{g}$ & 0 & +0.05 & +0.1 & -0.004 \\
\hline \multicolumn{5}{|l|}{2} \\
\hline Upstream ACh $40 \mu \mathrm{g}$ & +356 & +10.6 & -7.1 & +0.484 \\
\hline Downstream ACh $40 \mu \mathrm{g}$ & +278 & +9.6 & -8.6 & +0.434 \\
\hline \multicolumn{5}{|l|}{ Stenosis } \\
\hline Upstream ACh $40 \mu \mathrm{g}$ & +36 & +1.2 & -5.7 & +0.435 \\
\hline Downstream ACh $40 \mu \mathrm{g}$ & +61 & +1.7 & -0.7 & -0.008 \\
\hline \multicolumn{5}{|l|}{3} \\
\hline Upstream ACh $40 \mu \mathrm{g}$ & +174 & +10.2 & -24.2 & +0.890 \\
\hline Downstream ACh $40 \mu \mathrm{g}$ & +172 & +9.8 & -16.9 & +0.323 \\
\hline \multicolumn{5}{|l|}{ Stenosis } \\
\hline Upstream ACh $40 \mu \mathrm{g}$ & +16 & -1.4 & -21.5 & +0.295 \\
\hline Downstream ACh $40 \mu \mathrm{g}$ & +17 & +0.1 & -0.2 & -0.005 \\
\hline \multicolumn{5}{|l|}{4} \\
\hline Upstream ACh $40 \mu \mathrm{g}$ & +462 & +40.0 & -22.1 & +0.574 \\
\hline Downstream ACh $40 \mu \mathrm{g}$ & +540 & +31.4 & -29.1 & +0.305 \\
\hline \multicolumn{5}{|l|}{ Snare } \\
\hline Upstream ACh $40 \mu \mathrm{g}$ & +118 & +5.3 & -29.5 & +0.226 \\
\hline Downstream ACh $40 \mu \mathrm{g}$ & +3 & +0.1 & -0.0 & +0.001 \\
\hline \multicolumn{5}{|l|}{5} \\
\hline Upstream ACh $40 \mu \mathrm{g}$ & +50 & +2.2 & -21.2 & +0.247 \\
\hline Downstream ACh $40 \mu \mathrm{g}$ & +99 & +4.2 & -20.8 & +0.164 \\
\hline \multicolumn{5}{|l|}{ Stenosis } \\
\hline Upstream ACh $40 \mu \mathrm{g}$ & -3 & -0.3 & -23.4 & +0.193 \\
\hline Downstream ACh $40 \mu \mathrm{g}$ & +18 & +1.0 & -2.1 & -0.016 \\
\hline \multicolumn{5}{|l|}{6} \\
\hline Upstream ACh $40 \mu \mathrm{g}$ & +92 & +7.8 & -22.2 & +0.298 \\
\hline Downstream ACh $40 \mu \mathrm{g}$ & +173 & +17.2 & -10.5 & +0.408 \\
\hline \multicolumn{5}{|l|}{ Stenosis } \\
\hline Upstream ACh $40 \mu \mathrm{g}$ & +11 & +0.9 & -16.3 & +0.900 \\
\hline Downstream ACh $40 \mu \mathrm{g}$ & +1 & +0.9 & -1.2 & +0.001 \\
\hline \multicolumn{5}{|l|}{7} \\
\hline Upstream ACh $40 \mu \mathrm{g}$ & +189 & +3.4 & -21.3 & +0.240 \\
\hline Downstream ACh $40 \mu \mathrm{g}$ & +351 & +7.8 & -19.1 & +0.320 \\
\hline \multicolumn{5}{|l|}{ Stenosis } \\
\hline Upstream ACh $40 \mu \mathrm{g}$ & -3 & -0.1 & -24.3 & +0.198 \\
\hline Downstream ACh $40 \mu \mathrm{g}$ & -8 & -0.1 & -0.7 & -0.005 \\
\hline \multicolumn{5}{|l|}{8} \\
\hline Upstream ACh $40 \mu \mathrm{g}$ & +956 & +15.6 & -16.4 & +0.149 \\
\hline Downstream ACh $40 \mu \mathrm{g}$ & +487 & +8.8 & -28.8 & +0.322 \\
\hline \multicolumn{5}{|l|}{ Stenosis } \\
\hline Upstream ACh $40 \mu \mathrm{g}$ & +8 & +0.2 & -13.6 & +0.196 \\
\hline Downstream ACh $40 \mu \mathrm{g}$ & +32 & +0.8 & -0.16 & -0.008 \\
\hline
\end{tabular}


which ensured that distally injected ACh could not reach the test segment. Analysis of haemodynamic variables was made off-line using CHART 5 software (AD Instruments).

\section{Statistical analysis}

InSTAT software (Graph Pad, San Diego, CA, USA) was used to carry out paired Student's $t$-tests and STAтMATE software (Graph Pad) for carrying out power calculations.

\section{Results}

In the absence of a stenosis, i.e. with unrestricted blood flow through the iliac artery, upstream and downstream ACh both caused increased blood flow, resulting in dilatation of the test segment (Fig. 2, left panel). With the stenosis in place, the increases in flow and shear stress were small and below the threshold change required to elicit shear stress-induced arterial dilatation (Kelly \& Snow 2007), except for the upstream injection in experiment 4 (Table 1). Downstream ACh injection had no effect on proximal arterial diameter. To be certain that the injected higher dose of ACh was reaching the femoral vascular bed, pressure in the downstream artery, was recorded in four pigs. Pressure fell by 29, 4, 53 and $62 \mathrm{mmHg}$ in experiments 5-8 respectively, proving that ACh exerted an effect on resistance vessels. In all experiments, upstream injection of ACh still produced a large dilatation (Figs 2 and 3, right-hand panels). The results for changes in shear stress and diameter for the eight experiments in the presence of a stenosis are given in Figure 3. The total results from individual experiments are listed in Table 1, and the statistical results are given in Table 2, when ACh was injected in the absence of a stenosis downstream, the increases in arterial diameter are predicted due to increased flow and wall shear stress. When this response was blocked by a stenosis, down- stream injection of ACh caused a statistically significant reduction in diameter accompanying the fall in arterial pressure (Table 2). While the sample size is not sufficient to completely confirm this reduction in diameter, the possibility of a dilatation is ruled out. In the presence of a stenosis, the statistically significant dilatation, in spite of reduced arterial pressure, with upstream injection of ACh indicates a direct effect of $\mathrm{ACh}$ independent of shear stress.

\section{Discussion}

The results of this study show that the change in diameter in a feeding conduit artery is mediated by the established shear stress response. This response has been the subject of previous studies (Snow et al. 2001, Markos et al. 2002, Kelly et al. 2006, Kelly \& Snow 2007) and our conclusion is based on the fact that when an increase in shear stress is prevented the artery does not dilate (Figs 2 and 3; Tables 1 and 2).

We experienced some difficulty in these experiments in making the correct adjustment of the stenosis, a wellknown haemodynamic problem; the stenosis during upstream ACh injection in experiment 4 (Table 1) was not sufficiently tight, so that a considerable flow increase and shear stress-induced arterial dilatation could have resulted. However, the preservation of arterial dilatation in these circumstances in the other seven experiments gives us confidence that the direct effect of ACh was present locally. In experiment 7 , the snare was too tight so that ACh actually produced a decrease in blood flow and shear stress. Nevertheless, the large decrease in pressure distal to the stenosis, produced by downstream ACh injection, confirms that the drug reached its target, while the lack of effect on proximal arterial diameter further confirms absence of a retrograde signal. We also obtained the same results irrespective of whether the stenosis was placed proximal or distal to the diameter measurement site, thereby ruling out the possibility that the stenosis blocked the
Figure 3 Results in the presence of a stenosis. Lines join the two measurements of each of the eight experiments, proximal and distal refer to the injection site for acetylcholine (ACh) $(40 \mu \mathrm{g})$. Left: The changes in shear stress are very small due to the critical flow limiting stenosis. Right: With the below threshold shear stress stimulus, distal injection of ACh has no effect on arterial diameter, but arterial dilatation is present with the direct stimulus of proximally injected ACh.
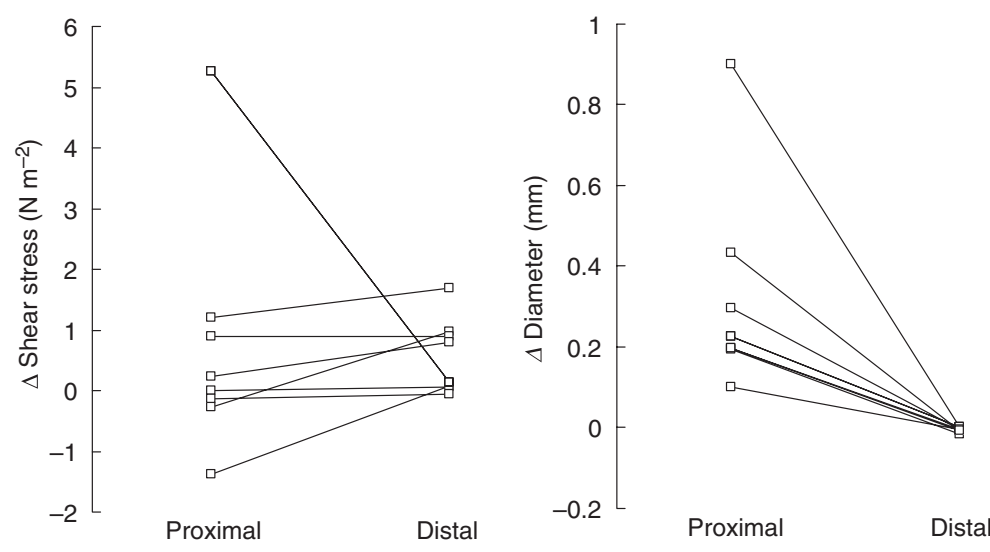
Table 2 Results of paired $t$-tests on each variable applied to the entire set of experiments with 7 degrees of freedom (d.f.), $n=8$

\begin{tabular}{|c|c|c|c|c|c|}
\hline Variable & Intervention & $\begin{array}{l}\text { Mean increase } \\
\text { peak response }\end{array}$ & SD & $P$ & $t$ \\
\hline \multicolumn{6}{|l|}{ No stenosis } \\
\hline Blood flow & Upstream ACh & $+326 \mathrm{~mL} \mathrm{~min}^{-1}$ & 290 & 0.0155 & 3.18 \\
\hline Shear stress & Upstream ACh & $+13.7 \mathrm{~N} \mathrm{~m}^{-2}$ & 12.1 & 0.0151 & 3.12 \\
\hline Arterial pressure & Upstream ACh & $-18.1 \mathrm{mmHg}$ & 6.2 & $<0.0001$ & 8.247 \\
\hline Arterial diameter & Upstream ACh & $+0.388 \mathrm{~mm}$ & 0.248 & 0.003 & 4.429 \\
\hline \multicolumn{6}{|l|}{ With stenosis } \\
\hline Blood flow & Upstream ACh & $+23 \mathrm{~mL} \mathrm{~min}^{-1}$ & 40 & 0.1519 & 1.608 \\
\hline Shear stress & Upstream ACh & $+0.7 \mathrm{~N} \mathrm{~m}^{-2}$ & 2 & 0.3374 & 1.03 \\
\hline Arterial pressure & Upstream ACh & $-17.1 \mathrm{mmHg}$ & 9.5 & 0.0014 & 5.08 \\
\hline Arterial Diameter & Upstream ACh & $+0.318 \mathrm{~mm}$ & 0.255 & 0.0096 & 3.531 \\
\hline \multicolumn{6}{|l|}{ No stenosis } \\
\hline Blood flow & Downstream ACh & $+306 \mathrm{~mL} \mathrm{~min}^{-1}$ & 156 & 0.0009 & 5.541 \\
\hline Shear stress & Downstream ACh & $+12.8 \mathrm{~N} \mathrm{~m}^{-2}$ & 8.5 & 0.0036 & 4.28 \\
\hline Arterial pressure & Downstream ACh & $-17.7 \mathrm{mmHg}$ & 8.4 & 0.0006 & 5.93 \\
\hline Arterial diameter & Downstream ACh & $+0.301 \mathrm{~mm}$ & 0.106 & $<0.0001$ & 8.015 \\
\hline \multicolumn{6}{|l|}{ With stenosis } \\
\hline Blood Flow & Downstream ACh & $+15.5 \mathrm{~mL} \mathrm{~min}^{-1}$ & 22.2 & 0.0899 & 1.967 \\
\hline Shear stress & Downstream ACh & $+0.57 \mathrm{~N} \mathrm{~m}^{-2}$ & 0.6 & 0.0349 & 2.61 \\
\hline Arterial pressure & Downstream ACh & $-0.6 \mathrm{mmHg}$ & 0.7 & 0.0525 & 2.332 \\
\hline Arterial diameter & Downstream ACh & $-0.006 \mathrm{~mm} *$ & 0.005 & 0.025 & 2.84 \\
\hline
\end{tabular}

*This experiment had a $95 \%$ power to detect a smallest average difference between pairs of $0.0076 \mathrm{~mm}$ with a significance level (alpha) of 0.05 (two-tailed). Thus, the sample size was inadequate to confirm a constriction, but as the direction of change was negative, absence of dilatation is confirmed.

retrograde signal. Pohl et al. (1986) also injected ACh upstream with a distal stenosis to prevent flow increases. This produced a dilatation of the segment of the artery above the stenosis, which was abolished by removing its endothelium. This is similar to our result, and showed that the local response of the artery is mediated by the endothelium. However, they did not exclude a contribution from retrograde signals by injecting ACh downstream in the presence of a stenosis.

As mentioned, these results exclude the possibility that the change in diameter in a large feeding artery is due to a retrograde signal transmitted through the tissue of the arterial wall. That such a mechanism was a reasonable possibility is likely due to the undoubted existence of EDHF, the release of which causes hyperpolarization of endothelial cells which spread to smooth muscle cells along the arterial wall through gap junctions (Baersachs et al. 1996, Busse \& Fleming 2006, De Wit et al. 2006, Sandow \& Tare 2007). The present study does not challenge the EDHF concept. Our concern is merely a question of the distance that this signal can travel along an artery. The distance travelled must be finite because, if hyperpolarization in one site of the arterial tree spreads to the rest of the tree, the tree would always be maximally dilated! All previous investigators write in terms of distances of the magnitude of about $3 \mathrm{~mm}$ (Emerson \& Segal 2000) and studies in a single arteriole confirm that the spread of the conducted response was very limited (Rivers 1997). The distances we are concerned with in a moderately sized mammal are in the order of centimetres, not millimetres. Therefore, our results are of more relevance to humans and may have interesting implications for disease (Noble et al. 2008), than results obtained in a small mammal with an ilio-femoral artery distance of millimetres. However, it should be noted that only a small number of healthy animals were used in the present study and therefore, the findings may not be directly applicable to human disease. We have failed to find any experiments in which retrograde transmission has been measured over an arterial distance of centimetres.

However, there are other possible reasons why we failed to detect retrograde signalling. Experiments described in the literature in which this phenomenon is apparent were performed on more peripheral small arteries often in vitro, perfused with artificial salt solutions. This leads to four possibilities: (1) the retrograde signalling does not affect large central conduit arteries such as the pig iliac artery; (2) the pig 
femoral artery like the rat's does not transmit hyperpolarization from the endothelial cells to the smooth muscle cells (Sandow et al. 2002); (3) the distance travelled by the retrograde signal is limited and the degree of hyperpolarization declines at a distance to an ineffectual level; or (4) the pig is an exceptional species showing lack of the phenomenon.

Takano et al. (2004) also offered a possible explanation for the inability of hyperpolarization to reach the iliac artery. They suggested that in larger arteries, the increasing number of smooth muscle layers will provide a growing current sink to dissipate the hyperpolarization and thus reduce the extent of longitudinal spread. However, this theory is contradicted by the findings of Chaytor et al. (2005) in which the decay of hyperpolarization within the media of the rabbit iliac artery was relatively limited, even though staining for smooth muscle actin revealed the presence of approx. 10 layers of smooth muscle cells. Contrary to these findings in the rabbit (Sandow et al. 2002), it has been shown that hyperpolarization does not occur in the smooth muscle cells of the femoral artery of the rat (in vitro) after blockade of NO and prostaglandins.

In conclusion, downstream injection of $\mathrm{ACh}$, in the presence of a stenosis, does not cause dilatation of the iliac artery. This finding seems to disprove the ascending signalling hypothesis of Hilton (1959), as it would be expected that exposure of the downstream endothelium to ACh would have caused considerable EDHF-mediated hyperpolarization of cells within the arterial and arteriolar walls. However, it clearly fails to produce a retrograde signal. Under similar conditions of stenosis, the response of the test segment to upstream ACh indicates that this is a direct effect upon the endothelial cells.

\section{Conflict of interest}

None of the authors have any conflict of interest to declare.

This study was supported by grants from the Coronary Thrombosis Trust.

\section{References}

Baersachs, J., Popp, R., Hecker, M., Sauer, E., Fleming, I. \& Busse, R. 1996. Nitric oxide attenuates the release of endothelium derived hyperpolarising factor. Circulation 94, 3341-3347.

Busse, R. \& Fleming, X. 2006. Vascular endothelium and blood flow. Handb Exp Pharmacol 176, 43-78.

Chaytor, A., Bakker, L., Edwards, D. \& Griffiths, T. 2005. Connexin-mimetic peptides dissociate electrotonic EDHF- type signalling via myoendothelial and smooth muscle gap junctions in the rabbit iliac artery. Br J Pharmacol 144, 108114.

De Wit, C., Hoepf, B. \& Wolfle, S. 2006. Endothelial mediators and communication through vascular gap junctions. Biol Chem 387, 3-9.

Emerson, G. \& Segal, S.S. 2000. Electrical coupling between endothelial cells and smooth muscle cells in hamster feed arteries; role in vasomotor control. Circ Res 87, 474-479.

Griffith, T.M. 2002. Endothelial control of vascular tone by nitric oxide and gap junctions: a haemodynamic perspective. Biorheology 39, 307-318.

Griffith, T., Chaytor, A., Taylor, H., Giddings, B. \& Edwards, D. 2002. cAMP facilitates EDHF-type relaxations in conduit arteries by enhancing electrotonic conduction via gap junctions. Proc Natl Acad Sci USA 99, 6392-6397.

Hilton, S.M. 1959. A peripheral arterial conducting mechanism underlying dilatation of the femoral artery and concerned in functional vasodilation in skeletal muscle. J Physiol 149, 93-111.

Kelly, R. \& Snow, H. 2007. Characteristics of the response of the iliac artery to wall shear stress in the anaesthetised pig. J Physiol 582, 731-743.

Kelly, R., Ruane O’Hora, T., Noble, M., Drake-Holland, A. \& Snow, H. 2006. Effect of hyperglycaemia on endothelial dependent dilatation in the iliac artery of the anaesthetized pig. J Physiol 573, 133-145.

Markos, F., Hennessy, B.A., Fitzpatrick, M., O’Sullivan, J. \& Snow, H. 2002. Reverse arterial wall stress causes nitric oxide-dependent vasodilatation in the anaesthetised dog. Pflugers Arch 445, 51-54.

Noble, M.I.M., Drake-Holland, A.J. \& Vink, H. 2008. Hypothesis: arterial glycocalyx dysfunction is the first step in the atherothrombotic process. Q J Med doi: 10.1093, qmed/ hen 024 .

Pohl, U., Holtz, J., Busse, R. \& Bassenge, E. 1986. Crucial role of endothelium in the vasodilator response to increased flow in vivo. Acta Physiol Scand 8, 37-44.

Rivers, R.J. 1997. Cumulative conducted vasodilation within a sifgle arteriole and the maximum conducted response. Am J Physiol 273, H310-H316.

Sandow, S. \& Tare, M. 2007. C-type natriuretic peptide: a new endothelium-derived hyperpolarizing factor? Trends Pharmacol Sci 28, 61-67.

Sandow, S.L., Tare, M., Coleman, H., Hill, C. \& Parkington, H. 2002. Involvement of myoendothelial gap junctions in the actions of endothelium derived hyperpolarising factor. Circ Res 90, 1108-1113.

Snow, H.M., Markos, F., O’Regan, D. \& Pollock, K. 2001. Characteristics of arterial wall shear stress which cause endothelium-dependent vasodilatation in the anaesthetized dog. J Physiol 531, 843-848.

Takano, H., Dora, K., Spitaler, M. \& Garland, C. 2004. Spreading dilatation in rat mesenteric arteries associated with calcium independent endothelial cell hyperpolarisation. J Physiol 556, 887-903. 